\title{
Perancangan Alat Lampu Dengan Sistem Sleep
}

\author{
Mario Indriawan \\ Fakultas Science and Technic \\ Universitas Bina Nusantara \\ indriawan17@gmail.com
}

\author{
Fanny Fransisca \\ Fakultas Science and Technic \\ Universitas Buddhi Dharma \\ stelovfan@ymail.com
}

\author{
Dram Renaldi \\ Fakultas Science and Technic \\ Universitas Buddhi Dharma \\ dramrenaldi@gmail.com
}

\begin{abstract}
Abstrak- Penghematan listrik! Mungkin slogan ini yang sering diungkapkan oleh pemerintah melalui berbagai cara agar masyarakat dapat mengerti dan bisa menghemat penggunaan sumber daya listrik. Berbagai cara terus dilakukan untuk menghemat penggunaan sumber daya listrik ini, namun dalam pelaksanaannya masih banyak pihak yang seolah - olah tidak memperdulikan himbauan dari pemerintah ini. Cara termudah yang bisa dilakukan dalam rangka penghematan sumber daya listrik ini adalah dengan mematikan lampu apabila tidak diperlukan. Alat ini dibuat sebagai pengembangan dari alat yang pernah ada, yaitu otomatisasi lampu dengan menggunakan sensor gerak dan sensor infra merah. Melihat ada bebrapa kelemahan yang ada dari kedua jenis sensor tersebut, maka alat ini dibuat dengan tidak menggunakan senor melaikan dengan mikrokontroler ATmega8535 yang dihubungkan dengan Relay SPDT sebagai saklar otomatis untuk pengontrolan alat secara keseluruhan. Setelah melalui pengujian dan juga pengajuan kuesioner kepada 25 orang responden, hasilnya alat ini dapat diterima sebagai alat pengontrolan lampu baru, yang dapat mengurangi beban penggunaan dari sumber daya listrik. Kemampuan alat ini sebagai pengontrol lampu yang beroperasi pada tegangan rendah dan mampu untuk mengontrol peralatan yang memiliki sumber tegangan lebih besar diharapkan mampu menjadi solusi dari masalah penggunaan sumber daya listrik yang berlebihan. Penulis menyadai bahwa masih terdapat banyak kekurangan baik dari penulisan dan juga dari alat pengontrol lampu ini, untuk itu perlu di kembangkan kembali agar alat ini menjadi lebih baik lagi.
\end{abstract}

Kata Kunci-Alat, Lampu, Mikrokontroler ATmega8535.

\section{Pendahuluan}

Penghematan listrik! Mungkin slogan ini yang sering diungkapkan dan digembor - gemborkan oleh pemerintah melalui berbagai cara agar masyarakat dapat mengerti dan bisa menghemat penggunaan sumber daya listrik. Berbagai cara terus dilakukan untuk menghemat penggunaan sumber daya listrik ini, namun dalam pelaksanaannya masih banyak pihak yang seolah - olah tidak memperdulikan himbauan dari pemerintah ini.

Cara termudah yang bisa dilakukan dalam rangka penghematan sumber daya listrik ini adalah dengan mematikan lampu apabila tidak diperluakan. Melalui berbagai media, pemerintah sudah berusaha melakukan himbauan kepada masyarakat, agar mau mematikan lampu di rumah masing masing apabila tidak diperlukan.
Hal ini menjadi permasalahan baru dimana tidak semua orang mau mendengarkan, bahkan hanya segelintir masyarakat saja yang mau mendengarkan himbauan dari pemerintah tersebut. Pada jaman yang serba modern ini setelah ditemukannya lampu oleh Thomas Alva Edison, masyarakat modern pada umunya tidak bisa hidup tanpa menggunakan lampu. Kenyataan ini semakin ironis ditambah dengan munculnya generasi baru yang tidak pernah meraskan hidup tanpa penerangan dari cahaya lampu. Umumnya mereka menggunakan lampu dengan sesuka hatinya, tanpa perduli berapa banyak sumber daya listik yang telah digunakan.

Selain itu apabila melihat dari perkembangan dari penggunaan lampu pada saat ini, seperti lampu jalanan yang sudah mengunakan sensor suhu atau cahaya, memang sudah banyak penggunaan lampu yang lebih efisien. Namun suhu ataupun cuaca itu sendiri merupakan besaran yang tidak pasti dan kadang kurang akurat dalam mendeteksi seberapa besar parameter yang digunakan agar lampu tersebut dapat bekerja melalui sensornya.

Untuk itu, dengan adanya permasalahan ini, maka dibuatlah "Perancangan Alat Lampu Dengan Sistem Sleep " dengan menggunakan mikrokontroler ATmega8535. Mikrokontroler jenis ATmega merupakan jenis mikrokontroler yang paling banyak berada dipasaran. Selain karena harganya terjangkau, mikrokontroler ATmega8535 adalah jenis yang paling banyak digunakan untuk pemrograman robotik khususnya di Indonesia, karena memiliki jumlah PIN yang dapat dikonfigurasi sebanyak 40 PIN. Untuk itu alat ini diharapkan mampu untuk mengontrol penggunaan listrik pada lampu kamar, lampu taman, lampu jalan, sehingga diharapkan dapat menghemat penggunaan dari sumber daya itu sendiri.

\section{TinjauAn PUSTAKA}

\section{A. Tinjauan Institusi / Jurnal}

1) Jurnal "Perancangan Aplikasi Sistem Otomatisasi Lampu Menggunakan Sensor Gerak Berbasis Mikrokontroler PIC 16F877A, Patriot Lumban Raja. 2013 - Universitas Advent Indonesia"

Dalam penelitian yang ada di jurnal ini metode penelitian yang digunakan berupa "Waterfall Method". Struktur pemrograman dalam perancangan sistem adalah didefinisikan sebagai cara - cara dari tiap komponen yang saling berkaitan dengan yang lain. 


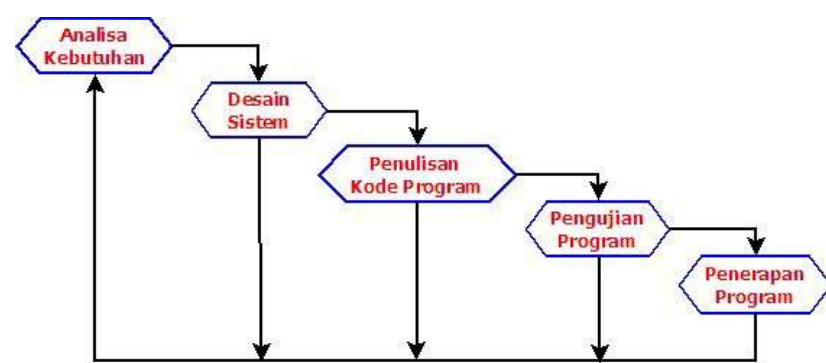

Gambar 1. Diagram Waterfall Sistem

Dimana adapun hasil dan penjelasan dari jurnal ini adalah bahwa rangkaian otomatisasi lampu siap bekerja bila rangkaian utama dan rangkaian beban yang telah terhubung dengan sumber tegangan 220 Volt AC. Rangkaian terhubung dengan sumber tegangan dan pada posisi automatis, berarti sensor PIR siap mendapat respon. Pada saat pertama kali menghidupkan rangkaian maka sensor belum dapat langsung memberikan respon. Hal ini karena rangkaian membutuhkan waktu untuk warm up sebelum beroperasi normal. Kondisi tersebut adalah normal karena dalam rangkaian digunakan komponen yang sangat sensitive seperti sensor PIR. Namun untuk dapat bekerja normal hanya membutuhkan kurang lebih1 (satu) menit. Begitu pula pada saat mengubah setting, maka rangkaian akan memerlukan waktu untuk berubah kenilai setting yang baru. Bila sudah terjadi warm up, maka sensor telah siap dan rangkaian utama siap mendapat trigger untuk mengaktifkan saklar otomatis.

2) b. Jurnal "Perancangan Pengatur Lampu Otomatis untuk Penghemat Energi Berbasis Mikrokontroler AT89C52, Herlan dan Lintang Dwi Feridiani. 2012 - Puslit Informatika LIPI"

Dengan hasil dan pembahasan jurnal yang mengatakan bahwa Interfensi cahaya luar berasal dari lampu yang dapat diatur intensitas cahayanya. Saat tidak ada intervensi cahaya dari luar (mati), lampu di dalam maket menyala maksimal. Osiloskop menunjukkan beda phasa sebesar 45o. Pada beda phasa tersebut intensitas lampu sebesar 321,3 lux. Saat intervensi dari luar diberikan cahaya lampu yang redup, intensitas lampu di dalam maket sedikit berkurang, namun masih terang. Beda phasa lampu sebesar $60 \mathrm{o}$ dan tingkat luminasi menurun, menjadi 247,3 lux. Saat intervensi dari luar diberikan cahaya yang terang, intensitas lampu mulai berkurang, menjadi redup sebesar 84,6 lux. Dan saat intervensi dari luar dimaksimalkan, lampu di dalam maket meredup hingga hampir mati, dengan tingkat luminasi 50,2 lux.

Data yang diperoleh di atas menunjukkan, adanya interfensi cahaya dari luar dengan tingkat intensitas yang berbeda-beda mempengaruhi intensitas lampu maket, ditunjukkan dengan beda phasa dan tingkat luminasi lampu yang berubah-ubah. Hal ini disebabkan karena sistem pengatur lampu berupaya untuk mempertahankan tingkat luminasi ruangan tetap konstan pada nilai 250 lux, dengan memanfaatkan cahaya dari luar ruangan. Bila intensitas cahaya dari luar maket cukup kuat, maka sistem mengatur agar intensitas lampu dikurangi, sehingga daya yang digunakan akan berkurang, begitu pula sebaliknya. Sehingga sistem akan menggunakan daya secara efisien. Data-data yang didapatkan menunjukkan sistem yang dirancang sudah tepat, sesuai dengan tujuan perancangan.

Permasalahan yang muncul adalah bahwa dalam pelaksanaannya untuk melakukan otomatisasi lampu dengan menggunakan sensor gerak dan juga sensor infra merah ini diperlukan beberapa perangkat pendukung yang dituntut untuk selalu bekerja setiap saat. Sensor utama dari masing - masing perancangan alat ini memiliki life time tersendiri yang harus dipelihara ketahanannya. Untuk itu timbul beberapa masalah baru seperti:

- Daya tahan dari sensor gerak dan sensor infra merah yang digunakan.

- Keakuratan dari kedua sensor tersebut, apabila ada makhluk lain (hewan) selain manusia yang masuk kedalam ruangan.

Dengan permasalahan yang muncul diatas, peneliti juga menunjukan beberapa alternatif pemecahanan masalah, sebagai berikut:

- Mengubah penggunaan sensor gerak dan sensor infra merah menjadi penggunaan parameter timer untuk melakukan proses otomatisasi.

- Membuat model perancangan alat terbaru yang lebih akurat dalam pelaksanaannya, yakni dengan menggunakan perancangan alat lampu dengan sistem sleep.

Dengan adanya penyelesaian masalah ini, maka peneliti mengharapkan alat yang digunakan dapat berjalan sesuai dengan keinginan dari user yang dapat leluasa mengatur seberapa lama lampu tersebut akan digunakan.

\section{B. Perancangan Interface/Hardware}

1) Tampilan Hardware

a) Tampilan Alat

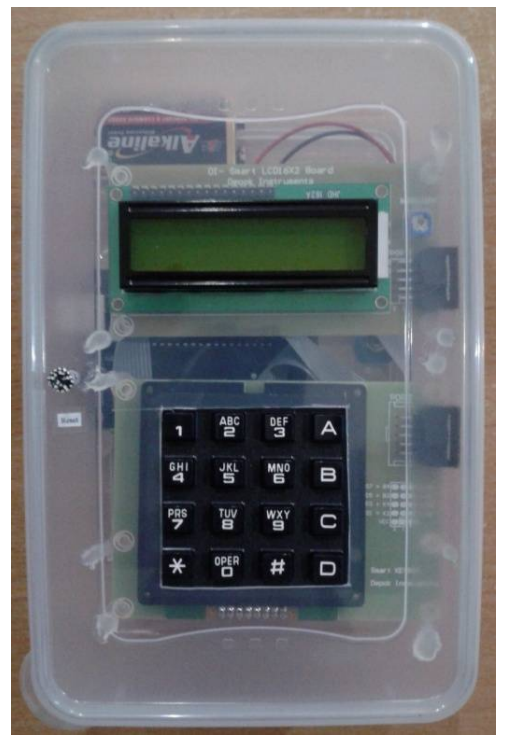

Gambar 2. Hasil Jadi Alat Tampak Luar 


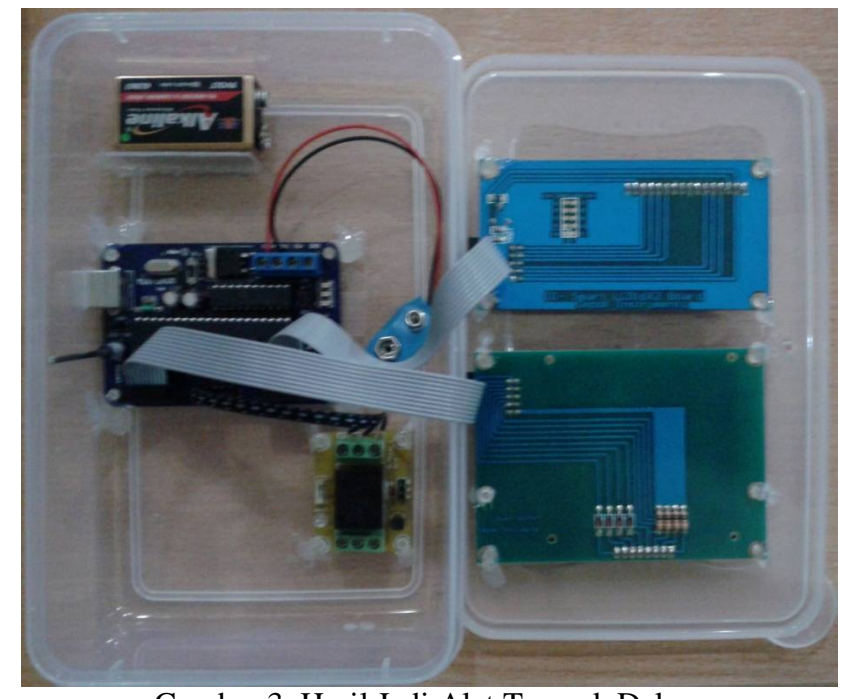

Gambar 3. Hasil Jadi Alat Tampak Dalam

Sesuai dengan dua gambar diatas bahwa alat yang dibuat disusun menjadi satu buah komponen lengkap, yang penggunaannya akan dihubungkan dengan lampu.

\section{b) Hasil Jadi Mikrocontroller ATmega8535}

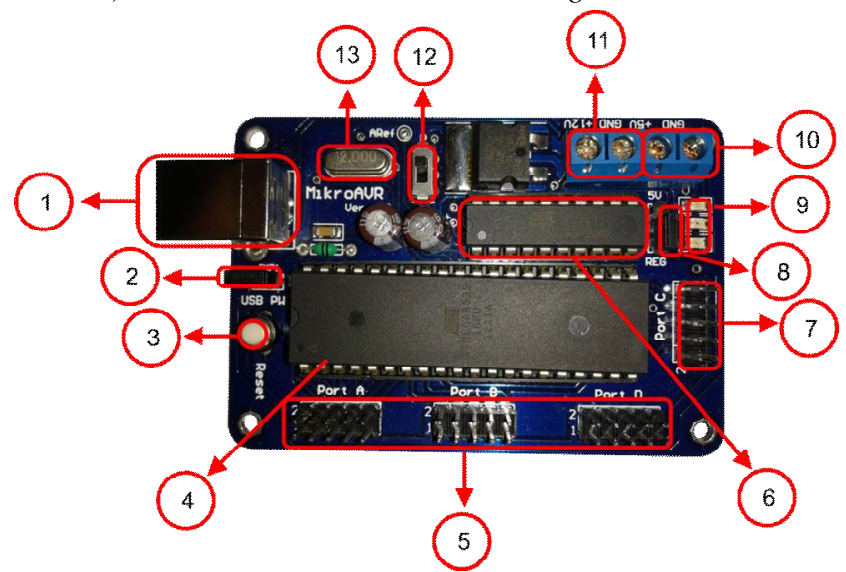

Gambar 4. Hasil Jadi Board Mikrokontroler ATmega8535

Keterangan dari masing - masing komponen diatas adalah sebagai berikut:

- Konektor USB ke Serial.

Fungsi dari konektor ini adalah untuk media transfer data dari port Serial ke port USB yang terdapat pada $\mathrm{PC}$ atau laptop. Bisa juga digunakan sebagai pemberi power dari USB.

- Jumper power USB ke mikro.

Digunakan sebagai jumper untuk mengatur jumlah arus yang masuk dari USB menuju mikro.

- Tombol reset.

Berfungsi untuk me-reset program yang sudah berada pada mikro.

- Chip ATmega8535.
Jurnal SISFOKOM, Volume 04, Nomor 01, Maret 2015

- \& 7. Port A, Port B, Port C, Port D.

Pada board ini diberikan 4 buah port yang bisa digunakan untuk menghubungkan mikro dengan komponen - komponen lain seperti LCD dan keypad

- Chip AtTiny2313 untuk downloader.

- Jumper power 5 volt selector.

- LED signal

Terdapat 3 buah LED yang digunakan sebagai indikatior dari board mikro, biru menandakan USB power, hijau menandakan mikro power, merah menandakan mikro sedang melakukan read / write data.

- Power 5 volt tanpa regulator.

- Regulator power 7 - 24 volt.

- Switch selector untuk download ke mikro.

- Clock generator Xtal 11.0592.

\section{c) Hasil Jadi LCD 162}

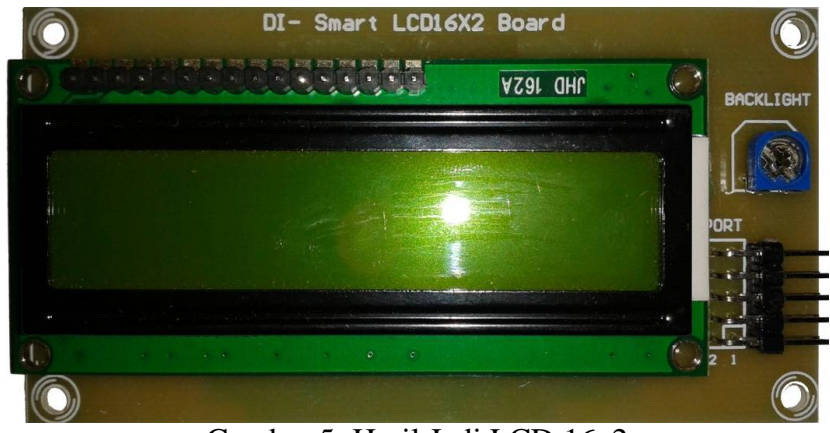

Gambar 5. Hasil Jadi LCD 16x2

Pada gambar diatas, dapat diketahui bahwa LCD berukuran 16 × 2 yang berarti memiliki panjang baris 16 karakter dan juga lebar kolom sebanyak 2 karakter, dapat digunakan untuk menampilakan karakter yang sudah diprogram melalui mikrokontroler. Papan LCD tersebut memiliki tombol pengaturan cahaya atau yang biasa disebut dengan backlight dan juga memiliki konektor port agar dapat dihubungkan dengan mikro.

d) Keypad $4 \times 4$

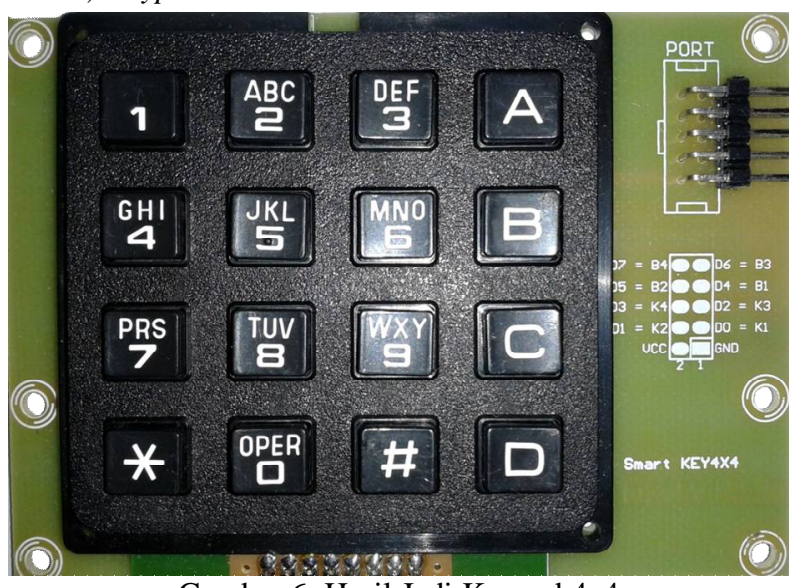

Gambar 6. Hasil Jadi Keypad 4x4 
Pada gambar diatas yang memiliki 16 tombol yang dapat digunakan untuk input data kemudian akan ditampilkan ke LCD melaui port konektor yang dihubungkan ke mikrokontroler.

e) Relay

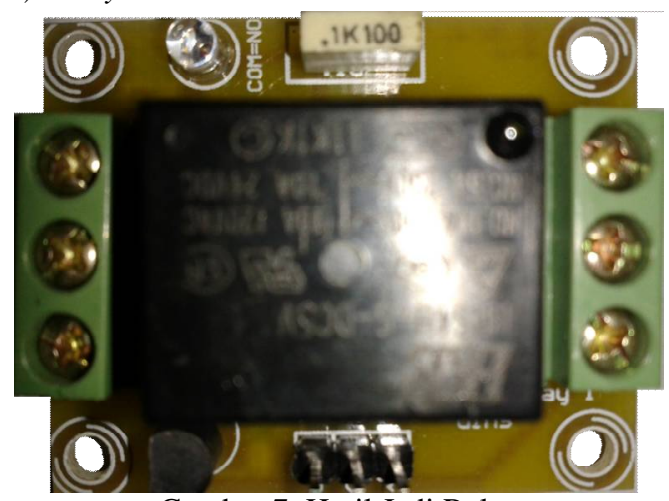

Gambar 7. Hasil Jadi Relay

Sesuai dengan gambar diatas, bahwa relay yang digunakan menggunakan tegangan rendah sebesar 5 volt, sehingga dapat langsung disambungkan dengan mikrokontroler. Relay ini temasuk kedalam relay bertipe SPDT (Single Pole Double Throw).

\section{2) Tampilan Layar $L C D$}

Pada gambar 4.37 Hasil Tampilan Layar Awal terdapat kalimat pembuka yang berisikan nama dari penulis dan juga institusi tempat penulis melanjutkan pendidikan di sekolah tinggi kejuruan.

\section{a) Layar Petunjuk}

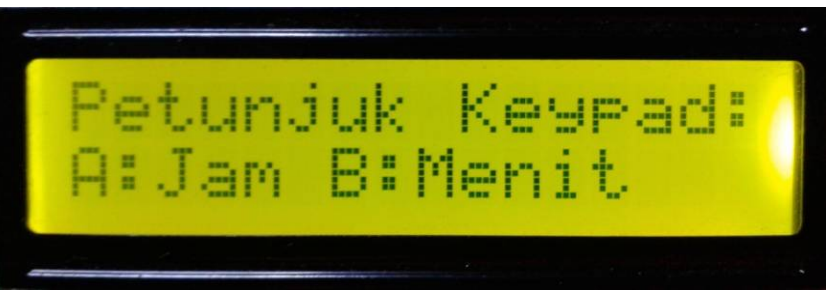

Gambar 8. Hasil Tampilan Layar Petunjuk

Gambar diatas menunjukan halaman yang berisikan tentang cara menggunakan keypad dengan masing - masing fungsinya, dimana tombol A berfungsi untuk memasukkan data kedalam variabel jam, tombol B berfungsi untuk memasukkan data kedalam variabel menit, tombol $\mathrm{C}$ berfungsi untuk menghapus data yang ditampilkan pada layar LCD, dan yang terakhir tombol D berfungsi untuk menjalankan program apabila nilai sudah di input oleh user.

b) Layar Input Data

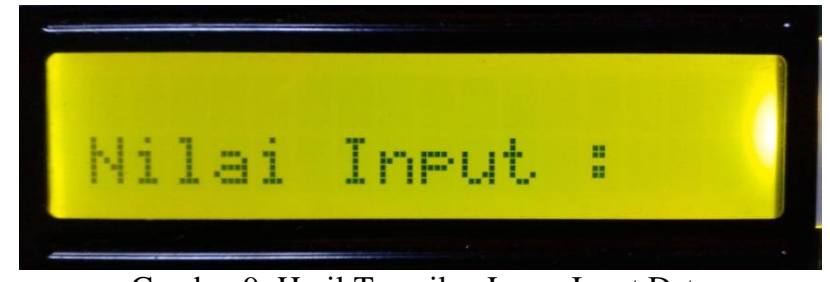

Gambar 9. Hasil Tampilan Layar Input Data

Gambar diatas merupakan tempat user memasukkan nilai untuk variabel jam dan menit.

c) Layar Program Waktu

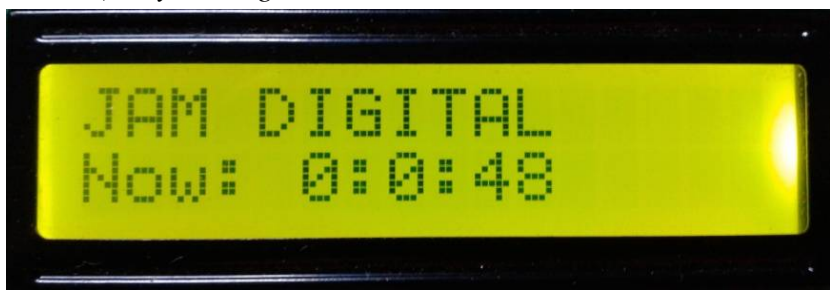

Gambar 10. Hasil Tampilan Layar Program Waktu

Gambar diatas menampilkan program waktu countdown yang menjalankan hasil input.

\section{d) Layar Program Berakhir}

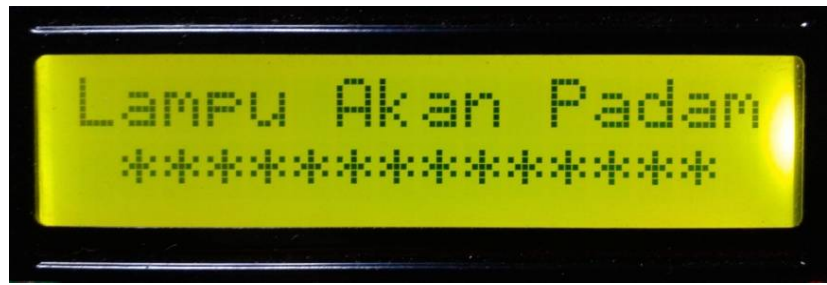

Gambar 11. Hasil Tampilan Layar Program Berakhir

Sesuai dengan gambar bahwa layar akan menampilkan pesan sebelum lampu akan padam.

e) Layar Pesan Error pada Input Menit

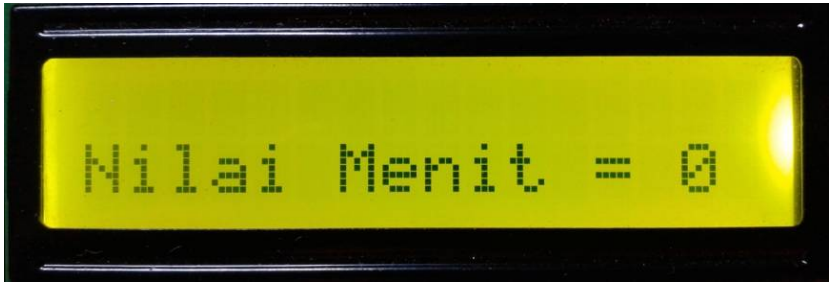

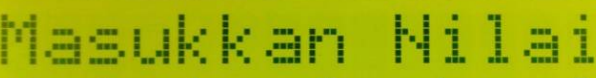

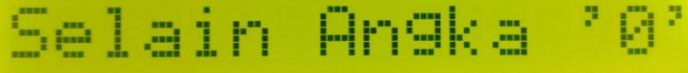




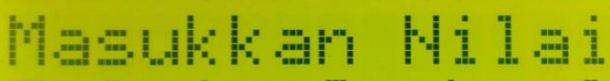

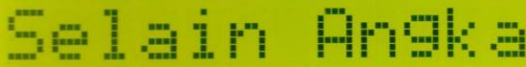
1
M. $=4 k 6 m$ Hi $=$ i

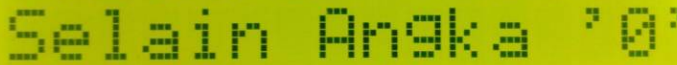
Menit

Sesuai dengan gambar diatas, layar yang akan memberikan keterangan apabila user memasukkan nilai $=0$ atau nilai $>60$ dan akan memerintahkan untuk memasukkan kembali nilai ke variabel menit.

\section{f) Layar Pesan Error Saat Input Jam}

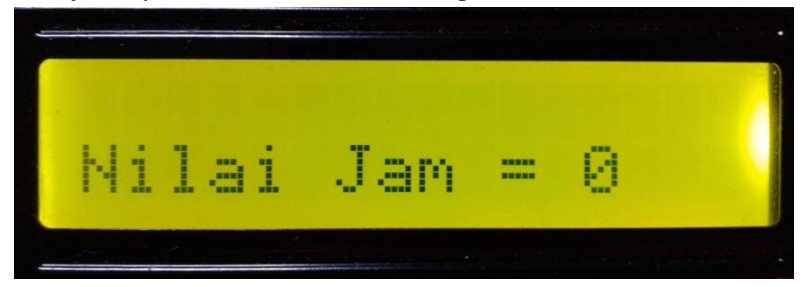

H: $=4 \mathrm{k}=\mathrm{m}+\mathrm{i}=\mathrm{i}$

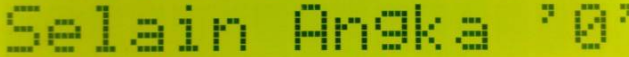
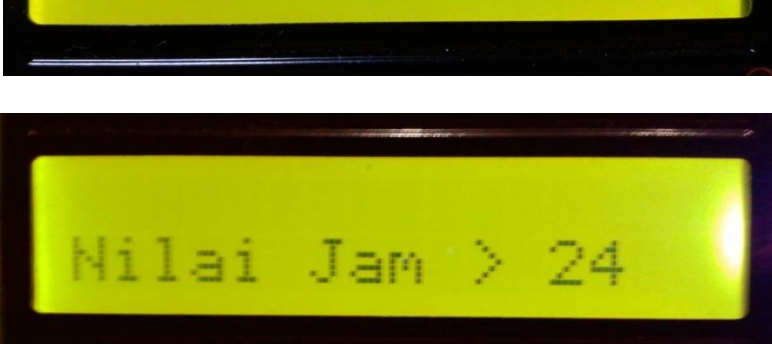

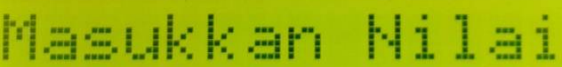
\%

Gambar 13. Hasil Tampilan Layar Pesan Error Pada Input Jam
Sesuai dengan gambar diatas, layar yang akan memberikan keterangan apabila user memasukkan nilai $=0$ atau nilai $>24$ dan akan memerintahkan untuk memasukkan kembali nilai ke variabel jam.

\section{Hasil PEngolahan Kuisioner}

Setelah alat ini selesai, peneliti mengujinya kepada user. Pada tahap ini alat lampu dengan sistem sleep diujikan kepada masyarakat umum dan juga mahasiswa yang sudah mengerti tentang bagaimana menggunakan suatu alat. Evaluasi terhadap alat ini dilakukan dengan cara menyebar kuesioner kepada 25 responden. Kemudian responden memberikan tanggapan dan sarannya melalui kuesioner.

Tabel 1. Hasil Kuesioner

\begin{tabular}{|c|c|c|c|}
\hline No & Pertanyaan & Ya & Tidak \\
\hline 1. & $\begin{array}{l}\text { Apakah anda mengetahui } \\
\text { tentang mikrokontroler? }\end{array}$ & 15 & 10 \\
\hline 2. & $\begin{array}{l}\text { Apakah anda pernah } \\
\text { menggunakan mikrokontroler } \\
\text { sebelumnya? }\end{array}$ & 13 & 12 \\
\hline 3. & $\begin{array}{l}\text { Apakah anda pernah } \\
\text { mengontrol alat dengan sistem } \\
\text { sleep? }\end{array}$ & 23 & 2 \\
\hline 4. & $\begin{array}{lrr}\text { Apakah dalam kehidupan } \\
\text { sehari - hari anda pernah } \\
\text { menonton sebuah } & \text { acara } \\
\text { televisi, kemudian } & \text { anda } \\
\text { tertidur dan lupa untuk } \\
\text { mematikan lampu? }\end{array}$ & 19 & 6 \\
\hline 5. & $\begin{array}{l}\text { Pernahkah terpikir oleh Anda, } \\
\text { untuk melakukan kontrol } \\
\text { terhadap lampu? }\end{array}$ & 9 & 16 \\
\hline 6. & $\begin{array}{l}\text { Apakah anda pernah } \\
\text { menggunakan alat seperti ini } \\
\text { sebelumnya? }\end{array}$ & 5 & 20 \\
\hline 7. & $\begin{array}{l}\text { Setelah mencoba alat ini, } \\
\text { apakah alat ini dapat } \\
\text { digunakan dengan mudah? }\end{array}$ & 23 & 2 \\
\hline 8. & $\begin{array}{l}\text { Apakah tampilan dari alat ini } \\
\text { sudah sesuai sebagai alat } \\
\text { pengontrol lampu? }\end{array}$ & 22 & 3 \\
\hline 9. & $\begin{array}{l}\text { Menurut anda, apakah alat ini } \\
\text { dapat membantu dalam upaya } \\
\text { penghematan listrik? }\end{array}$ & 21 & 4 \\
\hline 10. & $\begin{array}{l}\text { Menurut anda, apakah alat } \\
\text { pengontrolan lampu dengan } \\
\text { sistem sleep yang telah dibuat } \\
\text { perlu dikembangkan lebih }\end{array}$ & 24 & 1 \\
\hline
\end{tabular}




\begin{tabular}{|c|c|c|c|}
\hline No & \multicolumn{1}{|c|}{ Pertanyaan } & Ya & Tidak \\
\hline & lanjut? & & \\
\hline
\end{tabular}

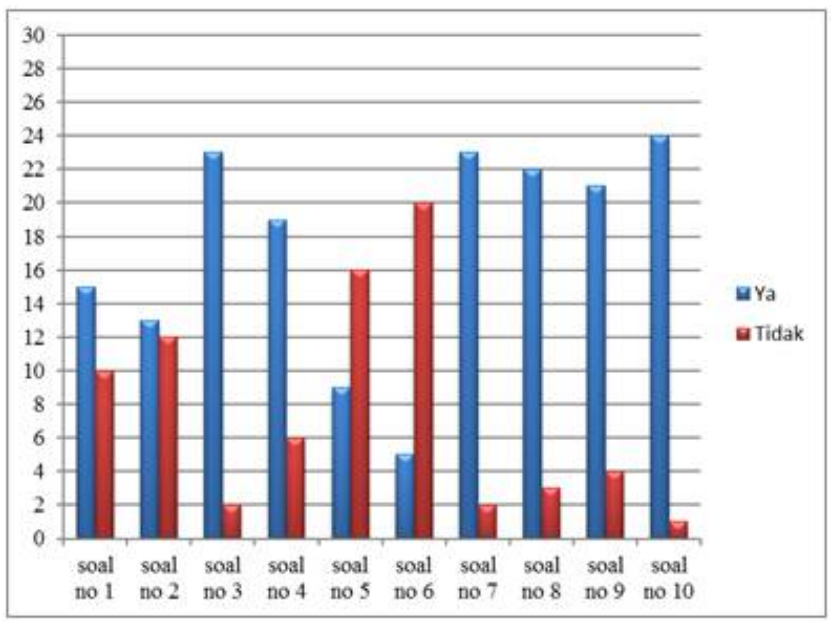

Gambar 14.Grafik Keseluruhan Hasil Kuesioner

\section{Penutup}

\section{A. Kesimpulan}

Setelah melakukan analisa, perancangan, uji coba program, serta evaluasi alat lampu dengan sistem sleep maka dapat ditarik kesimpulan sebagai berikut:

- Perancangan alat lampu dengan sistem sleep ini merupakan suatu bentuk alat pengontrolan baru, yang dapat menentukan kapan lamanya penggunaan dari sebuah lampu dengan sistem sleep agar dapat mengurangi penggunaan cahaya yang tidak diperlukan.

- Setelah dibuatnya alat lampu dengan sistem sleep ini dapat mengurangi penggunaan dari sumber daya listrik, yang biasanya terbuang pada saat lampu tidak dimatikan.

- Alat ini dapat berjalan dengan kapasitas tegangan yang tidak terlalu besar yakni sebesar 9 volt (baterai), namun dapat megontrol lampu yang berjalan pada kapasitas tegangan sebesar 220-230 volt.

\section{B. Saran}

Saran untuk pengembangan lebih lanjut mengenai alat lampu dengan sistem sleep adalah sebagai berikut:

- Program ini dikonfigurasi dengan menggunakan bahasa pemrograman $\mathrm{C}$, dan diharapkan dapat mengembangkan alat lampu dengan sistem sleep sesuai dengan bahasa pemrograman yang dikuasai.

- Biaya dari board mikrokontroler, LCD 16x2, Keypad $4 \times 4$, relay SPDT tersebut terbilang cukup mahal, carilah alternatif penggunaan dari masing - masing komponen dan bila memungkinkan diharapkan untuk merakit sendiri.
- Tambahkan relay sebagai saklar elektornik agar dapat mengontrol jumlah lampu yang lebih banyak, sehingga memungkinkan untuk mengurangi beban dari penggunaan sumber daya listrik.

- Gunakan LCD dengan spesifikasi yang lebih tinggi dan dapat menampilkan karakter - karakater khusus agar tampilan dari alat ini menjadi lebih baik.

\section{DAFTAR PUSTAKA}

[1] Syahrul, 2012, Mikrokontroler AVR Atmega8535, Bandung: Informatika.

[2] Winoto, Ardi, 2008, Mikrokontroler AVR Atmega8/32/16/8535 dan Pemrograman dengan Bahasa $C$ pada WinAVR, Bandung: Informatika.

[3] Wardana, Lingga, 2006, Belajar Mikrokontroler AVR Seri Atmega8535 Simulasi, Hardware dan Aplikasi, Yogyakarta: Andi.

[4] Ary Heryanto, M. dan Wisnu, A.P, 2007, Pemrograman Bahasa C Untuk Mikrokontroler ATmega8535, Yogyakarta: Andi.

[5] Supriyanto, Aji, 2005, Pengantar Teknologi Informasi, Jakarta: Salemba Infotek.

[6] Mazidi, M.A. dan Mazidi, Janice, 2010, The AVR Microcontroller and Embedded System, USA: Prentice Hall PTR.

[7] Pitowarno, Endra, 2006, Desain Robotika, Kontrol dan Kecerdasan Buatan, Yogyakarta: Andi.

[8] Sjukani, Moh, 2010, Struktur Data (Algoritma \& Struktur Data 2) Dengan C, C++ Edisi 4, Bekasi: Mitra Wacana Media. 